\title{
PELAKSANAAN SENAM KESEGARAN JASMANI DALAM UPAYA MENGGALAKKAN GERAKAN MASYARAKAT SEHAT (GERMAS) DI KELURAHAN MAHARANI KECAMATAN RUMBAI
}

\author{
Eka Maya Saputri ${ }^{(1)}$ Kiki Megasari ${ }^{(2)}$, Tania Valentina ${ }^{(3)}$ \\ STIKes Hang Tuah Pekanbaru \\ email : maya.eka72@yahoo.com
}

\begin{abstract}
ABSTRAK
Gerakan Masyarakat Hidup Sehat (GERMAS) merupakan suatu tindakan sistematis dan terencana yang dilakukan secara bersama-sama oleh seluruh komponen bangas dengan kesadaran, kemauan dan kemampuan berprilaku sehat utuk meningkatkan kualitas hidup. GERMAS secara nasional dimulai dengan berfokus pada 3 kegiatan yaitu melakukan aktifitas fisik selama 30 menit perhari, mengkonsumsi buah dan sayur, dan memeriksakan kesehatan secra rutin. Senam aerobik adalah senam untuk meningkatkan kesegaran jasmani yang bukan untuk dijadikan suatu ajang perlombaan ataupun prestasi. Aerobik juga termasuk ke dalam olahraga preventif yang bisa dilakukan secara massal. Kegiatan sosialisasi dan praktik senam kesegaran jasmani yang telah diselenggarakan pada tanggal 28 november 2019 pukul 10.00 WIB dilapangan voli di kelurahan Maharani kecamatan Rumbai Kota Pekanbaru, yang dihadiri oleh seluruh warga RW 002 RT 002 tujuan pelaksanaan kegiatan ini yaitu untuk menjaga kesehatan jantung dan kebugaran badan. kehidupan manusia tidak terlepas dari aktivitas fisik dimana aktivitas fisik merupakan bagian dari kehidupannya. Banyak orang membutuhkan yang namanya olahraga, karena jasmani seseorang perlu dijaga agar tubuh tetap sehat, bugar dan tidak kaku. Banyak orang membutuhkan yang namanya olahraga, karena jasmani seseorang perlu dijaga agar tubuh tetap sehat, bugar dan tidak kaku.
\end{abstract}

\section{Kata Kunci : Senam Aerobic, jasmani, Kelurahan Maharani}

\section{ABSTRACT \\ IMPLEMENTATION OF PHYSICAL FRESH GYNAMICS IN EFFORTS TO IMPROVE HEALTHY COMMUNITY MOVEMENT (GERMAS) IN KELURAHAN MAHARANI KECAMATAN RUMBAI}

The Healthy Living Community Movement (GERMAS) is a systematic and planned action carried out jointly by all components of the nation with awareness, willingness and ability to behave in a healthy manner to improve the quality of life. GERMAS. National GERMAS begins by focusing on 3 activities, namely doing physical activity for 30 minutes per day, consuming fruits and vegetables, and having regular health checks. Aerobic exercise is exercise to improve physical fitness which is not used as a competition or achievement. Aerobics is also included in preventive sports that can be done en masse. Socialization activities and physical fitness exercises that were held on 28 November 2019 at 10.00 WIB in the volleyball field in Maharani village, Rumbai sub-district, Pekanbaru City, which was attended by all residents of RW 002 RT 002, the purpose of implementing this activity is to maintain heart health and body fitness. Human life is inseparable from physical activity 
where physical activity is a part of life. Many people need sports, because someone's body needs to be maintained so that the body remains healthy, fit and not stiff. Many people need sports, because one's body needs to be maintained so that the body remains healthy, fit and not stiff.

Keywords: Aerobic Gymnastics, physical, Maharani Village

\section{PENDAHULUAN}

Germas merupakan suatu tindakan sistematis dan terencana yang dilakukan secara bersama-sama oleh seluruh komponen bangas dengan kesadaran, kemauan dan kemampuan berprilaku sehat utuk meningkatkan kualitas hidup. GERMAS secara nasional dimulai dengan berfokus pada 3 kegiatan yaitu melakukan aktifitas fisik selama 30 menit perhari, mengkonsumsi buah dan sayur, dan memeriksakan kesehatan secra rutin. Melakukan aktifitas fisik merupakan salah satu upaya yang jarang dapat dilakukan masyarakat karena kesibukan yang dilakukannya. Namun dengan menyempatkan waktu untuk melakukan aktifitas fisik banyak manfaat yang dapat diperoleh diantaranya: membakar lemak yang tertupuk, melancarkan peredaran darah sehingga fungsi jantung dapat bekerja dengan baik, melatih kerja otot lebih baik, membugarkan tubuh dan menyehatkan badan. Salah satu upaya yang menarik dalam melakukan aktifitas fisik adalah melakukan senam kesegaran jasmani minimal selama 30 menit agar manfaatnya terasa untuk tubuh.

Dalam era modernisasi sekarang ini, kehidupan manusia tidak terlepas dari aktivitas fisik dimana aktivitas fisik merupakan bagian dari kehidupannya. Banyak orang membutuhkan yang namanya olahraga, karena jasmani seseorang perlu dijaga agar tubuh tetap sehat, bugar dan tidak kaku. Maka salah satu cabang olahraga senam aerobik sangat cocok untuk kebugaran tubuh.

Senam aerobic juga merupakan gerakan olahraga yang berguna menyelaraskan tubuh bagian atas dengan tubuh bagian bawah secara bersamaan.Sehingga dalam melakukan senam aerobik, dibutuhkan kelenturan serta kontinuitas gerakan yang sesuai dengan musik yang mengiringi Keuntungan melakukan senam aerobic menurut Lynne Brick adalah:

1. Jantung: otot-otot jantung akan lebih kuat dalam memompa darah untuk mengirimkan oksigen ke seluruh tubuh. 
2. Kekuatan otot akan lebih bertambah

\section{METODE PELAKSANAAN}

Metode yang demonstrasi yang di gunakan dalam pengabdian ini dengan menggunakan brosur dan flipchart dan memberikan contoh langsung pelksanaan senam aerobik kepada masyarakat,setlah di demonstrasikan maka remaja dievaluasi untuk mempraktekkan langsung seman aerobik. Bentuk kegiatan di lakukan berupa diskusi dengan menggunakan flipchart serta brosur di berikan kepada masyarakat.setelah diberikan pengetahuan tentang senam aerobik,maka akan di buka sesi tanya jawab

\section{HASIL DAN PEMBAHASAN}

\section{A. HASIL PELAKSANAAN}

a) Kegiatan berlangsung sesuai dengan jadwal yaitu Kamis , Tanggal 28 November 2019 di Lapangan voli kelurahan Maharani kecamatan Rumbai Kota Pekanbaru

b) Acara mulai pukul $08.00-10.00$ WIB

c) Partisipasi masyarakat yang hadir belum sesuai yang targetkan, banyak belum bisa hadir, yang ditargetkan sekitar 35 yang bisa hadir 25 orang

d) Tanggapan masyarakat yang mengikuti kegiatan senam kesegaran jasmani positif, serta masyarakat lebih bugar dan sehat dalam melakukan aktifitas. Masyarakat merasa senang dengan ada kegiatan ini

e) Masyarakat mendapatkan informasi tentang senam Aerobic dan kesehatan pengalaman gerak yang benar sesuai dengan prinsip - prinsip latihan secara sistematis

f) Masyarakat dapat mengembangkan kembali pengetahuan tentang senam Aerobic kepada masyarakat yang lebih luas.

\section{B. PEMBAHASAN}

Kegiatan sosialisasi dan praktik senam kesegaran jasmani yang telah diselenggarakan pada tanggal 28 november 2019 pukul 10.00 WIB dilapangan voli di kelurahan Maharani kecamatan Rumbai Kota Pekanbaru, yang dihadiri oleh seluruh warga RW 002 RT 002 tujuan pelaksanaan kegiatan ini yaitu untuk menjaga kesehatan jantung dan kebugaran badan. Kehidupan manusia tidak 
terlepas dari aktivitas fisik dimana aktivitas fisik merupakan bagian dari kehidupannya. Banyak orang membutuhkan yang namanya olahraga, karena jasmani seseorang perlu dijaga agar tubuh tetap sehat, bugar dan tidak kaku. Banyak orang membutuhkan yang namanya olahraga, karena jasmani seseorang perlu dijaga agar tubuh tetap sehat, bugar dan tidak kaku.
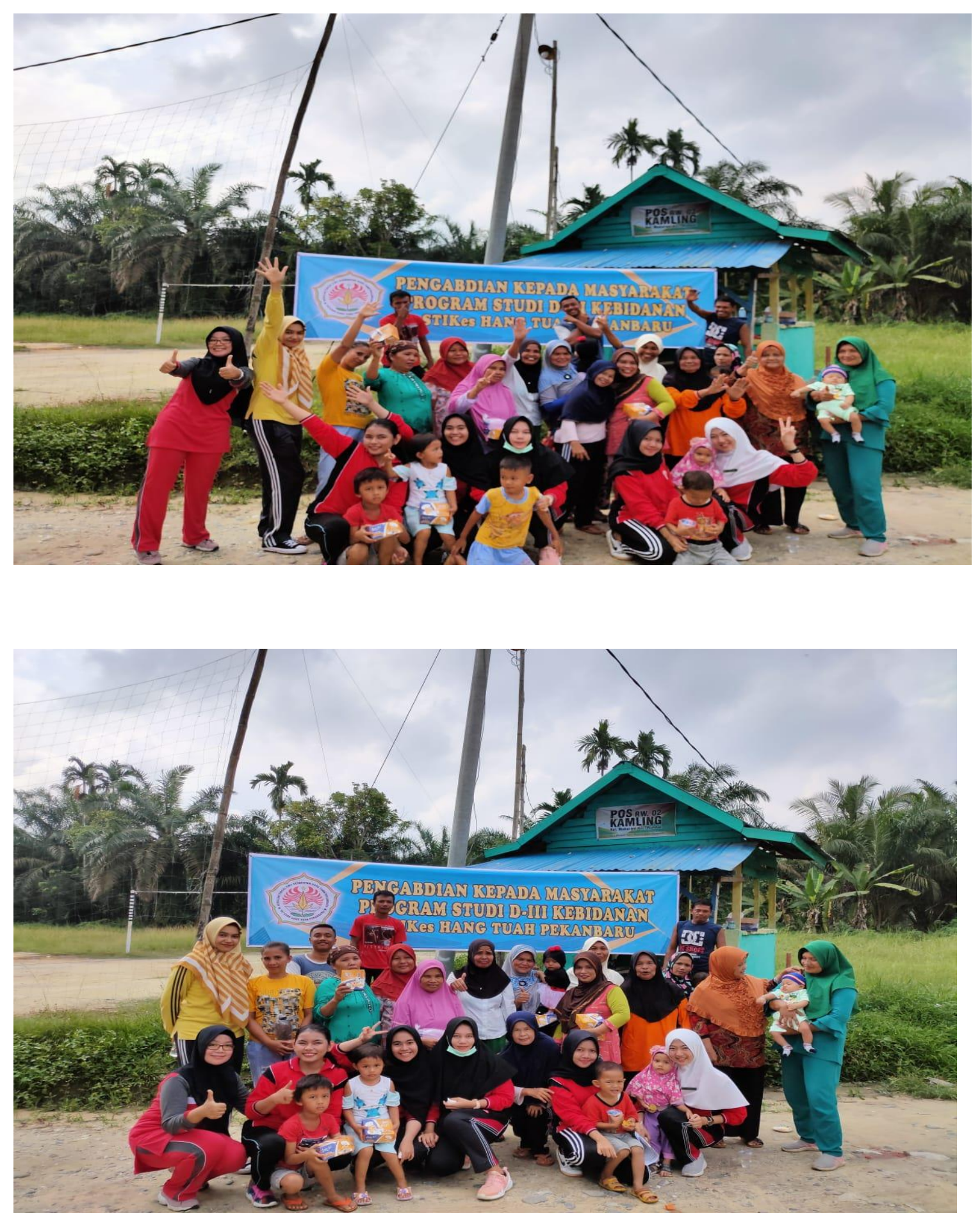


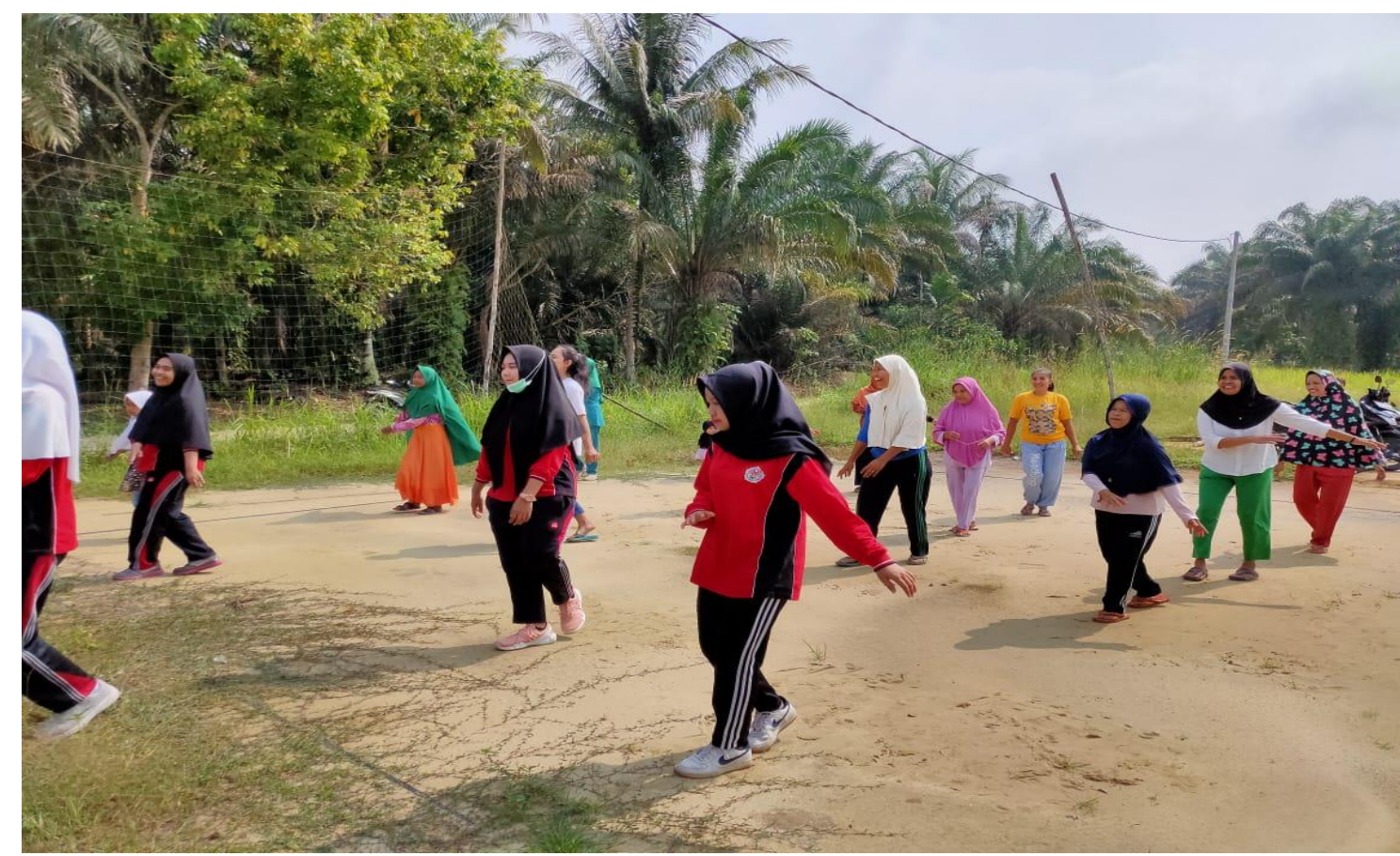

\section{KESIMPULAN}

a) Kegiatan berlangsung sesuai dengan jadwal yaitu Kamis , Tanggal 28 November 2019 di Lapangan voli kelurahan Maharani kecamatan Rumbai Kota Pekanbaru

b) Partisipasi masyarakat yang hadir belum sesuai yang targetkan, banyak belum bisa hadir, yang ditargetkan sekitar 35 yang bisa hadir 25 orang

c) Tanggapan masyarakat yang mengikuti kegiatan senam kesegaran jasmani positif, serta masyarakat lebih bugar dan sehat dalam melakukan aktifitas.
Masyarakat merasa senang dengan ada kegiatan ini

d) Masyarakat mendapatkan informasi tentang senam Aerobic dan kesehatan pengalaman gerak yang benar sesuai dengan prinsip - prinsip latihan secara sistematis

\section{DAFTAR PUSTAKA}

Budiyono, Kodrad. 2015. Amplikasi Senam Aerobik High Impact Dan Low Impact Terhadap Penrunan Presentase Lemak Tubbuh Pada Kepala Sekolah dasar SeKecamatan Banjarsari Surakarta. Jurnal Ilmiah.

Gilang, M. 2007. Pendidikan Dan Kesehatan. Ganeka Exact. Jakarta 
Fatmah. 2010. Gizi Usia Lanjut. PT Penerbit Erlangga. Jakarta.

Irianto, D.P. 2004. Pedoman Praktis Berolahraga. Yogyakarta: Andi Offset.

Kadir, A. 2005. Adaptasi Kardiovascular Terhadap Latihan Fisik. Surabaya: Universitas Wijaya Kusuma.

Marjana, W., Sudiana, I., dan Budiawan, M. 2014. Pengaruh Pelatihan
Shuttle Run Terhadap Kecepatan

Dan Kelincahan. Singaraja: EJurnal IKOM Pendidikan Ganesha Jurusan Ilmu Keolahragaan. Vol I.

Nala. 2011. Prinsip Pelatihan Fisik Olahraga. Denpasar: Universitas Udayana

putriiilarasati.blogspot.com/2013/11/makal ah-gerakan-senam-aerobikpenjaskes_874.html 